\title{
Research on Risk Evaluation of SME Financing based on Grey Theory
}

\author{
Wang Zhangliu \\ Zhengzhou Institute of Aeronautical Industry Management \\ 2 Da Xue Middle Road, Zhengzhou, 450015, China \\ E-mail: wzhangliu@126.com \\ Wang Lan \\ Zhengzhou Institute of Aeronautical Industry Management \\ 2 Da Xue Middle Road, Zhengzhou, 450015, China \\ E-mail: wanglan8002@126.com \\ Wang Kai (Corresponding author) \\ School of Business Administration, Henan University of Economics and Law \\ 80 Wen Hua Road, Zhengzhou, 450002, China \\ E-mail: wangkai8002@126.com
}

$\begin{array}{lcc}\text { Received: October 17, } 2011 & \text { Accepted: December 14, } 2011 & \text { Published: January 5, } 2011 \\ \text { doi:10.5430/ijfr.v3n1p73 } & \text { URL: http://dx.doi.org/10.5430/ijfr.v3n1p73 }\end{array}$

\begin{abstract}
Small and medium enterprises (SMEs) play an important role in China's impressive economic growth and make substantial contribution to employment and outputs in last decades. Nevertheless, a lot of bottlenecks and obstacles appear for further growth of SMEs, especially with respect to financing. SME financing is different from that of larger corporations, since they are younger and subject to more growth uncertainty than large firms, especially in developing countries. The main problems related to SME access to finance in China are the risk involved in performing bad loans is higher. So it is significant for managers and investors both in theoretical and practical fields to assess the financing risk of SMEs. This paper's aim is to propose an analytical framework of risk evaluation on SME financing based on grey theory. Firstly, this paper discusses the current SME financing in China. Secondly, it sets up a multi-hierarchy index system. Thirdly, it confirms the weight of every index with AHP and gave a general assessment by means of a grey clustering method. Finally, a case study is conducted to validate the evaluation model and the evaluation process.
\end{abstract}

Keywords: Small and Medium Enterprise, Financing Risk, Analytic Hierarchy Process, Grey Theory

\section{Introduction}

The availability of financing for SMEs have the subject of growing attention in recent years based on the role SMEs play in economics growth. Due to their private-ownership nature, entrepreneurial spirit, and the ability to adapt to the ever-changing environment, they contribute to sustainable growth and employment generation in a significant manner (Aung Kyaw, 2008). SMEs have unique characteristics on their own - they are naturally more labor intensive, easy to start up, focus on small markets, require lower investment, and promote customer intimacy.

It is now recognized that SMEs make a significant contribution to the socio-economic and political infrastructure of developed and developing countries as well as the nations in transition from command to market economies (Matlay\&Westhead, 2005). Small businesses with less than 100 workers in the United States represent one-third of domestic employment and sales value. SMEs in the EU account for about one-half of the total value added and two-thirds of labor force (European Union, 2005). SMEs contributed between 40 percent and 50 percent of manufacturing output in Chinese Taipei, Japan, and the Republic of Korea in the 1990s (Wattanapruttipaisan, 2003).

After moving towards a more market-oriented economy in 1978, China has experienced a decline in state-owned enterprises and an important expansion for small businesses (Walter, 2005). The role of SMEs in economic development 
is well documented for advanced economies and has been crucial in China's process of economic reform in last decades. There are currently more than 4000 million of China's small and medium enterprises, creating a nearly $60 \%$ of total GDP, taxes amounting to almost $50 \%$. Also, SMEs provide about $75 \%$ of urban employment opportunities.

Nevertheless, some bottlenecks and obstacles appear for further growth of SMEs, especially with respect to financing. The main problems related to SME access to finance in China are the risk involved in performing bad loans is higher than for larger firms. The evaluation of financing risk on small and medium enterprises is significant because the process can help us find the latent problem and reduce the risk. Evaluation and monitoring is warranted for measuring the efficiency and effectiveness of financing.

Multilevel grey evaluation method has been set out in this paper and has proven to be especially useful in the following instances: when data is only partially available; when using qualitative variables; or when using quantitative variables which are inaccessible to the professional and their quantification cannot therefore be deduced. We extend the AHP approach for the multicriteria assessment problem and propose to use a GAHP technique. The application of the multilevel grey evaluation to the field of financing risk on small and medium enterprises is an advance with respect to previous studies on the application of multi-criteria methods.

\section{Current SME Financing in China}

\subsection{Current State of SME Financing}

Comparing with state-owned corporation, private enterprises (majority of those are SMEs) rarely got favorable treatment from government in terms of subsidies, tax relaxation, and development loans. According to the World Bank Investment Climate Survey for China conducted for the period 2001 and 2002, SMEs in China face much more serious credit constraints and limited access to private finance than large firms even compared to other Asian countries (Dollar etal., 2003).

The Project Group of Research in Chinese Private Enterprises organized by China Industrial and Commercial Union and Research Commission of Chinese Private Business showed in a survey conducted in 2002 that self-accumulated money was the major source for starting up firms (approximately 55 percent), complemented by money borrowed privately (31.6 percent) and bank and Rural Credit Corporation loans (23.4 percent).SMEs, as opposed to larger publicly held businesses typically depend on external financing for liquidity. The evidence suggests that the private enterprises performance is associated with access to formal finance (bank loans), and more so, firms using formal financing sources grow faster than those financed by alternative channels (Cull \& Xu, 2005) (Maksimovic, Demirgüç-Kunt \& Ayyagari, 2008).

$<$ Table 1 about here>

Table 1 Shows that the financing preferences of owner/managers in China and US changed according to the development needs of their SMEs. Along with the growth of the enterprise, most of the owner/managers in the UK came to rely primarily on financial institutions. In contrast, owner/managers in the Chinese depended primarily on their immediate family and to a lesser extent on financial institutions (Hussain eta, 2005).

\subsection{Main Problems Related to SME Access to Financing}

From a credit risk point of view, SMEs are different from large corporate for many reasons. For example, Dietsch and Petey (2004) analyze a panel of German and French SMEs and conclude that they are riskier but have a lower asset correlation with each other than large businesses do.

There are scale economies in lending: per unit cost of screening and monitoring a loan decreases as the size of loan increases. If firm size is positively related to loan size, then the average cost of serving SMEs is larger than that for larger firms.

According to $\mathrm{Mu}$ (2002), since most SMEs are non-state enterprises, the risks involved in performing bad loans is higher than for larger firms where there are still more state-owned enterprises. Most of the SMEs rarely keep accounting records of their business in a systematic manner, which resulted in the information asymmetry between the business and the bank (Kanamori \& Zhao, 2004). To an extent, such costs of information asymmetry can be reduced through relationship banking or collateralized loans.

\section{Designing of Index as System}

Financing risk is any risk associated with any form of financing. Risk is probability of unfavorable condition; in financing sector it is the probability of actual return being less than expected return. Financing risk on small and medium enterprises is mainly credit risk, which is the risk of loss due to a debtor's non-payment of a loan or other line of credit. 
The financing risk on SMEs is resulted from financing and non-financing factors of enterprises, industry conditions and policy environment.

As shown in Table 2, this paper constructs the evaluation index system. There are three layers and thirteen evaluating indexes in the system. Financing risk on small and medium enterprises $(U)$ is the goal layer; the first index layer consist of three indexes: capital risk (U1), management risk (U2) and industry and policy risks (U3); the second index layer is the overall segments of the first index layer, including all the $\mathrm{a}_{\mathrm{ij}}$.

$<$ Table 2 about here $>$

\section{Multilevel Grey Evaluation Process}

\subsection{Computing the Weighted Set of Evaluating Factors by Using AHP}

The analytic hierarchy process method, is to express a complex decision-making problem as a sequential step-up hierarchy structure, compute the comparatively weightiness measurement of diversified decision-making behaviors, scheme and decision-making object under different rule and the whole rule, and then rank them according to the measurement, providing decision-making evidence for the decision-makers (Huang Jihong \& Ke Konglin, 2005) (Zhengdong Xu, Sifeng Liu \& Zhigeng Fang, 2008). The steps to solve the real problems using AHP method is as follows:

\subsubsection{Establishing the Problem's Hierarchy Structure}

According to the elementary analysis, divides the factors into several groups, and each group present a hierarchy. Then, ranks them as the sequence: the top layer, several relative middle layers and the bottom layer.

\subsubsection{Determining the Comparative Judgment Matrix}

$\mathrm{A}=\left\{\mathrm{a}_{\mathrm{ij}}\right\}_{\mathrm{m} \times \mathrm{n}}$

4.1.3 Calculating the Priority Vector to Weight the Elements of the Matrix

$W_{i}=\sqrt{\prod_{j=1}^{n} a_{i j}} / \sum_{i=1}^{n} \sqrt[n]{\prod_{j=1}^{n} a_{i j}}$

Thereinto, $\mathrm{i}, \mathrm{j}=1,2,3 \ldots \mathrm{n}$

$\lambda_{\text {MAX }}=\frac{1}{n} \sum_{i=1}^{n} \frac{(B W)_{i}}{W_{i}}$

4.1.4 Coincidence Rate (CR) Calculation

$\mathrm{CR}=\mathrm{CI} / \mathrm{RI}$

$\mathrm{CI}=\left(\lambda_{\operatorname{MAX}}-\mathrm{n}\right)(\mathrm{n}-1)$. When the $\mathrm{CR}<0.10$, we think the judgment matrix has satisfying consistency. Otherwise, we should adjust it to obtain the satisfying consistency.

\subsubsection{The Whole Hierarchy Sort}

The whole hierarchy sort. The whole hierarchy sort is to compute the weighted value of all factors' weightiness in this layer according to the upper layer by taking advantage of all results of the single hierarchy sort in the same layer. The single hierarchy sort is just the whole hierarchy sort for the top layer.

\subsection{Grey-AHP Evaluation Model}

\subsubsection{Constituting Comment Set of Evaluation Indicator}

We make out all the comment set of evaluation indicator. The assessment standard was divided into five grades: very low, low, common, high and very high. These are endowed with the following values: 5, 4, 3, 2, and 1. the grade is between two adjacent grades, which are marked by $4.5,3.5,2.5$, and 1.5 .

\subsubsection{Confirmation of Evaluation Sample Matrix}

Under the circumstance of determining the evaluation indicator system and the evaluation indicator weight, we can give evaluation indicators' values according to evaluation indicator $\mathrm{D}$. Then the evaluation sample matrix is as follows: 
$D=\left[\begin{array}{cccccc}d_{11}^{1} & d_{11}^{2} & \cdots & d_{11}^{k} & \cdots & d_{11}^{p} \\ d_{12}^{1} & d_{12}^{2} & \cdots & d_{12}^{k} & \cdots & d_{12}^{p} \\ \vdots & \vdots & \ddots & \vdots & \vdots & \vdots \\ d_{i j}^{1} & d_{i j}^{2} & \cdots & d_{i j}^{k} & \cdots & d_{i j}^{p} \\ \vdots & \vdots & \vdots & \vdots & \ddots & \vdots \\ d_{m n}^{1} & d_{m n}^{2} & \cdots & d_{m n}^{k} & \cdots & d_{m n}^{p}\end{array}\right]\left[\begin{array}{c}B_{1} \\ B_{2} \\ \vdots \\ B_{i j} \\ \vdots \\ B_{m n}\end{array}\right]$

4.2.3 Determining Evaluation Grey Cluster

First, We divided the grey cluster into five grades: "very low", "low", “"moderate", "high", "very high", e =1, 2, 3, 4, 5. The corresponding grey cluster and the first grey cluster are as follows:

The first grey cluster "very high" $(\mathrm{e}=1)$ : Grey number $\otimes_{1} \in[5, \infty]$, its whitenization function $f_{1}(x)$;

The second grey cluster "high" ( $\mathrm{e}=2)$ : Grey number $\otimes_{2} \in[0,4,8]$, its whitenization function $f_{2}(x)$

The third grey cluster "moderate" $(\mathrm{e}=3)$ :Grey number $\otimes_{3} \in[0,3,6]$, its whitenization function $f_{3}(x)$;

The fourth grey cluster "low" (e=4):Grey number $\otimes_{4} \in[0,2,4]$, its whitenization function $f_{4}(x)$

The fifth grey cluster "very low" $(\mathrm{e}=5)$ :Grey number $\otimes_{5} \in[0,1,2]$, its whitenization function $f_{5}(x)$

Hereinto,

$$
\begin{aligned}
& \left.f_{1}=\left\{\begin{array}{cc}
d_{i j}^{k} / 5 & d_{i j}^{k} \in\left[\begin{array}{ll}
0, & 5
\end{array}\right] \\
1 & d_{i j}^{k} \in[5, \quad \infty] \\
0 & d_{i j}^{k} \notin[0,
\end{array}\right]\right\} \\
& f_{2}=\left\{\begin{array}{cl}
d_{i j}^{k} / 4 & d_{i j}^{k} \in\left[\begin{array}{ll}
0, & 4
\end{array}\right] \\
\left(8-d_{i j}^{k}\right) / 4 & d_{i j}^{k} \in[4, \quad 8] \\
0 & d_{i j}^{k} \notin\left[\begin{array}{ll}
0, & 8
\end{array}\right]
\end{array}\right\}
\end{aligned}
$$

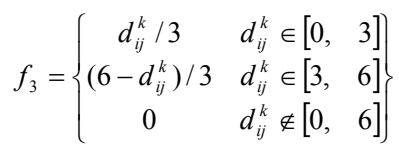

$$
\begin{aligned}
& f_{4}=\left\{\begin{array}{cl}
d_{i j}^{k} / 3 & d_{i j}^{k} \in[0,2] \\
\left(4-d_{i j}^{k} / 2\right. & d_{i j}^{k} \in[2,4 \\
0 & d_{i j}^{k} \notin[0,4
\end{array}\right\} \\
& f_{5}=\left\{\begin{array}{cl}
1 & d_{i j}^{k} \in\left[\begin{array}{ll}
0, & 1
\end{array}\right] \\
2-d_{i j}^{k} & d_{i j}^{k} \in\left[\begin{array}{ll}
1, & 2
\end{array}\right] \\
0 & d_{i j}^{k} \notin\left[\begin{array}{ll}
0, & 2
\end{array}\right]
\end{array}\right\}
\end{aligned}
$$

4.2.4 Calculate the Grey Weight

To one of the evaluation indicator $\mathrm{B}_{\mathrm{ij}}$, Candidate which belongs to the No.L(L=1,2,3,4,5) evaluation grey cluster has the grey evaluation coefficient:

$$
x_{i j e}=\sum_{k}^{p} f_{e}\left(d_{i j}^{k}\right)
$$

Then to the evaluation indicator $\mathrm{B}_{\mathrm{ij}}$, Candidate which belongs to all the evaluation grey cluster has the total quantity of Grey Evaluation:

$$
x_{i j}=\sum_{e=1}^{5} x_{i j e}
$$

The grey evaluation weight of No.e evaluation grey cluster:

$r_{i j}=x_{i j e} / x_{i j}$

The indicator $\mathrm{B}_{\mathrm{ij}}$ which belongs to the grey evaluation weight vectors

$r_{i j}=\left(\begin{array}{lllll}r_{i j 1}, & r_{i j 2}, & r_{i j 3}, & r_{i j 4}, & r_{i j 5}\end{array}\right)$

$\mathrm{A}_{\mathrm{i}}$ for all evaluation grey clusters has the grey evaluation weight matrix:

$R_{i j}=\left[\begin{array}{c}r_{i 1} \\ r_{i 2} \\ r_{i 3} \\ r_{i 4}\end{array}\right]=\left[\begin{array}{cccc}r_{i 11} & r_{i 12} & \cdots & r_{i 15} \\ r_{i 21} & r_{i 22} & \cdots & r_{i 25} \\ \vdots & \vdots & \ddots & \vdots \\ r_{i n 1} & r_{i n 2} & \cdots & r_{i n 5}\end{array}\right]$ 


\subsubsection{Calculating Total Appraisement Value}

First, evaluating $A_{i}$ synthetically, and its conclusion of comprehensive evaluation is $B_{i}$ :

$B_{i}=A_{i} \bullet R_{i}=\left(\begin{array}{lllll}b_{i 1}, & b_{i 2}, & b_{i 3}, & b_{i 4}, & b_{i 5}\end{array}\right)$

Then we obtained the grey assessment weight vector B of this firm by integrating every assessment grey classification.

$B=A \bullet R=\left(b_{1}, \quad b_{2}, \quad b_{3}, \quad b_{4}, b_{5}\right)$

According to the maximum principle, we can determine the grey grades of financing risk on small and medium enterprises. But sometimes judgments will be distorted because of losing too much information. At this time, we can deal with B further, make it single-value using formula 10 ,

here, $C=(5,4,3,2,1)$

$U=B \bullet C^{T}$

\section{Case Example}

\subsection{Weight Calculation}

The exact weights of main criteria and sub-criteria for financing risk assessment on SMEs are calculated with AHP method.

Thereinto,

$A=\left(\begin{array}{lll}0.58 & 0.31 & 0.11\end{array}\right)$

$A_{1}=\left(\begin{array}{llll}0.28, & 0.21, & 0.16, & 0.21\end{array}\right)$

$A_{2}=\left(\begin{array}{llll}0.38, & 0.24, & 0.21, & 0.17\end{array}\right)$

$A_{3}=\left(\begin{array}{llll}0.38, & 0.32,0.17,0.13\end{array}\right)$

5.2 Calculate the Matrix of Sample Assessment

Appraising one SMEs financing risk indicators by 5 experts, we construct the sample matrix D is as follow:

$$
D^{T}=\left[\begin{array}{lllllllllllll}
3.6 & 3.8 & 4.2 & 3.2 & 4.3 & 4.4 & 4.2 & 3.8 & 3.6 & 4.1 & 4.4 & 3.8 & 4.2 \\
4.2 & 4.2 & 3.9 & 2.9 & 4.6 & 4.2 & 3.8 & 3.7 & 3.5 & 4.8 & 4.3 & 4.1 & 4.0 \\
3.9 & 4.2 & 4.4 & 3.5 & 4.2 & 3.8 & 4.5 & 4.1 & 3.4 & 4.0 & 4.2 & 3.6 & 4.3 \\
4.1 & 4.3 & 4.2 & 3.2 & 4.5 & 3.6 & 4.2 & 4.3 & 2.9 & 3.9 & 3.9 & 4.2 & 3.9 \\
4.0 & 4.0 & 4.5 & 3.6 & 3.9 & 4.2 & 4.4 & 4.6 & 1.9 & 4.3 & 4.3 & 3.9 & 4.2
\end{array}\right]
$$

5.3 Calculate the Total Assessment

According to formula 3, 4, 5, 6, 7, we get the following matrixes:

$$
\begin{aligned}
& \begin{array}{l}
R_{1}=\left[\begin{array}{lllll}
0.319 & 0.387 & 0.273 & 0.021 & 0.000 \\
0.338 & 0.393 & 0.261 & 0.008 & 0.000 \\
0.357 & 0.392 & 0.247 & 0.004 & 0.000 \\
0.240 & 0.301 & 0.327 & 0.132 & 0.000 \\
0.366 & 0.389 & 0.241 & 0.004 & 0.000
\end{array}\right] \\
R_{2}=\left[\begin{array}{lllll}
0.272 & 0.367 & 0.337 & 0.024 & 0.000 \\
0.275 & 0.372 & 0.345 & 0.008 & 0.000 \\
0.338 & 0.381 & 0.261 & 0.020 & 0.000 \\
0.229 & 0.287 & 0.308 & 0.169 & 0.007
\end{array}\right]
\end{array} \\
& R_{3}=\left[\begin{array}{lllll}
0.327 & 0.393 & 0.268 & 0.012 & 0.000 \\
0.354 & 0.393 & 0.249 & 0.004 & 0.000 \\
0.315 & 0.382 & 0.279 & 0.024 & 0.000 \\
0.340 & 0.397 & 0.259 & 0.004 & 0.000
\end{array}\right] \\
& B_{1}=A_{1} \cdot R_{1}=\left(\begin{array}{lllll}
0.331, & 0.376, & 0.266, & 0.027, & 0.000
\end{array}\right) \\
& B_{2}=A_{2} \cdot R_{2}=\left(\begin{array}{lllll}
0.279, & 0.358, & 0.318, & 0.044, & 0.001
\end{array}\right) \\
& B_{3}=A_{3} \cdot R_{3}=\left(\begin{array}{lllll}
0.321, & 0.418, & 0.251, & 0.010, & 0.000
\end{array}\right)
\end{aligned}
$$


$R=\left[\begin{array}{lllll}0.331 & 0.376 & 0.266 & 0.027 & 0.000 \\ 0.279 & 0.358 & 0.318 & 0.044 & 0.001 \\ 0.321 & 0.418 & 0.251 & 0.001 & 0.000\end{array}\right]$

5.4 Calculate the Comprehensive Value

$U=B \bullet C^{T}=\left(\begin{array}{lllll}0.324, & 0.375, \quad 0.281, & 0.030, & 0.000\end{array}\right) \times(5, \quad 4, \quad 3, \quad 2, \quad 1)^{T}=4.02$

We obtained the comprehensive assessment value, obviously, $4<4.02<5$ and we can conclude that the integrated assessment of the financing risk on this firm is "very low"

\section{Conclusion}

The reliance of small businesses on banks' finance is not an uncommon fact as the same scenario happen in china and many parts of the world. In this paper we focus on the main issue concerning the SMEs financing. Evaluating the financing risk on small and medium enterprises is an important part for developing financing policy. Building scientific evaluation systems, making appropriate evaluation factors and attaching corresponding weight to them are of vital importance in evaluating correctly the financing risk on small and medium enterprises. We evaluate the financing risk by using the three level comprehensive evaluation of fuzzy mathematics. A multilevel grey evaluation has been set out in this paper and has proven to be especially useful. The application of the method in financing risk appraisal on small and medium enterprises is an improvement over previous work, in which both quantitative and qualitative variables are used where only partial information is available.

\section{References}

Aung K. (2008). Financing Small \& Medium Enterprises in Myanmar, IDE Discussion Paper. No. 148. [Online] Available: http://www.ide.go.jp/English/Publish/Download/Dp/148.html

Beck, T. \& Demirgüç-Kunt, A. (2006). Small \& Medium-Size Enterprises: Access to Finance as a Growth Constraint. Journal of Banking \& Finance 30, 2931-2943, http://dx.doi.org/10.1016/j.jbankfin.2006.05.009

Beck, T., Demirgüç-Kunt, A., \& Maksimovic, V. (2008). Financing Patterns around the World: Are Small Firms Different? Journal of Financial Economics 89, 467-87, http://dx.doi.org/10.1016/j.jfineco.2007.10.005

Cull, R. \& L. C. Xu. (2005). Institutions, Ownership, \& Finance: The Determinants of Profit Reinvestment Among Chinese Firms". Journal of Financial Economics, vol.77, pp:117-46, http://dx.doi.org/10.1016/j.jineco.2004.05.010

Dietsch, M. \& Joel, P. (2004). Should SME Exposures be Treated as Retail or as Corporate Exposures? A Comparative Analysis of Default Probabilities \& Asset Correlation in French \& German SMEs, Journal of Banking \& Finance 28,pp.773-788, http://dx.doi.org/10.1016/j.jbankfin.2003.10.006

Dollar, D. M., Hallward-Driemeier, A., Shi, S., Wallsten, S. W. \& Xu, L. C. (2003). Improving the Investment Climate in China, Investment Climate Assessment". World Bank \& International Finance Corporation, [Online] Available: http://citeseerx.ist.psu.edu/viewdoc/download?doi=10.1.1.198.7434\&rep=rep1\&type=pdf

European Union. (2005). Directorate-General for Enterprise, Innovation Tomorrow. Office for the Official Publications of the European Communities, Luxembourg.

Huang, J. \& Ke, K. (2005). The Evaluation \& Forecasting of Technology Innovation Risk Based on Fuzzy Comprehensive Evaluation, Scientific Management Research, No.3, pp.56-60, [Online] Available: http://epub.cnki.net/grid2008/detail.aspx?QueryID=4\&CurRec=1

Hussain etal. (2006). SME financing in the UK \& in China: a comparative perspective, Journal of Small Business \& Enterprise Development, Vol. 13, No. 4., pp. 584-599, http://dx.doi.org/10.1108/14626000610705769

Kanamori, T. \& Zhao, Z. (2004). Private Sector Development In the People's Republic of China. Asian Development Bank Insitute, Vol. 22 Iss: 4, pp.423 - 440, http://dx.doi.org/10.1108/17410390910975031

Maksimovic, V., Demirgüç-Kunt, A. \& Ayyagari, M. (2008). Formal Versus Informal Finance: Evidence from China. World Bank Policy Research Working Pape, http://dx.doi.org/10.1093/rfs/hhq030

Matlay, H. \& Westhead, P. (2005), Virtual teams \& the rise of e-entrepreneurship in Europe, International Small Business Journal, Vol. 23 No. 3, pp. 279-300, http://dx.doi.org/10.1177/0266242605052074

$\mathrm{Mu}$, Y. (2002). Impediments to SME Access to Finance \& Credit Guarantee Schems in China. Financial Sector Operations \& Policy Department, The World Bank, [Online] Available: 
http://papers.ssrn.com/sol3/papers.cfm?abstract_id=486204

Stephanou, C. \& Rodriguez, C. (2008). Bank Financing to Small- \& Medium-Sized Enterprises (SMEs) in Colombia. World Bank Policy Research Working Paper 4481, [Online] Available: http://papers.ssrn.com/sol3/papers.cfm?abstract_id=1086860

Thitapha, W. (2003). Four Proposals for Improved Financing of SME Development in ASEAN, Asian Development Review, vol. 20, no. 2, pp. 66-104. [Online] Available: http://www.asean.org/15658.pdf

Walter, G. F. (2005). Small \& medium enterprises financing in China, Universitat Pompeu Fabra in Organization.NO.11, 1-23. [Online] Available: http://www.bnm.gov.my/microsites/rcicc/papers/s6.garciafontes.pdf

Wang, Y. Z. (2004). Financing difficulties \& structural characteristics of SMEs in China, China \& World Economy, Vol. 12 No. 2, pp. 34-49, [Online] Available: http://en.iwep.org.cn/download/upload_files/qhlv5i45am1dlk5504kvtyqp20070504150058.pdf

Zhengdong, X., Sifeng, L. \& Zhigeng, F. (2007). Study on new method of GAHP, Proceedings of 2007 IEEE International Conference on Grey Systems \& Intelligent Services, pp.1390-1394

Table 1. SME Financing in China and UK

\begin{tabular}{|l|l|l|}
\hline \multicolumn{1}{|c|}{ Variables } & China (\%) & UK (\%) \\
\hline Initial funding & & \\
\hline Owner's savings & 22.2 & 14.3 \\
\hline Owner's immediate family & 70.1 & 57.7 \\
\hline Financial institutions & 7.7 & 28.0 \\
\hline Finance mix after two years & & \\
\hline Owner's savings & 22.2 & 28.3 \\
\hline Owner's immediate family & 53.3 & 15.7 \\
\hline Financial institutions & 24.5 & 56.0 \\
\hline Finance mix after two years & & \\
\hline Owner's savings & 12.5 & 14.3 \\
\hline Owner's immediate family & 67.0 & 7.1 \\
\hline Financial institutions & 20.5 & 78.6 \\
\hline Total & 100 & 100 \\
\hline
\end{tabular}


Table 2. The Evaluation Index System of Financing Risk on SME

\begin{tabular}{|c|c|c|c|}
\hline Goal layer & First Index Layer & \multicolumn{2}{|c|}{ Second Index Layer } \\
\hline \multirow{13}{*}{$\begin{array}{l}\text { Financing risk } \\
\text { on SMEs }(U)\end{array}$} & \multirow{5}{*}{$\begin{array}{c}\text { Capital risk of enterprise } \\
\left(\mathrm{U}_{1}\right)\end{array}$} & Debt paying ability & $\left(a_{11}\right)$ \\
\hline & & Cash flow & $\left(a_{12}\right)$ \\
\hline & & Enterprise profitability & $\left(a_{13}\right)$ \\
\hline & & Operation ability & $\left(a_{14}\right)$ \\
\hline & & Credit Level & $\left(a_{15}\right)$ \\
\hline & & Quality and ability of managers & $\left(a_{21}\right)$ \\
\hline & Management risk of enterprise & Marketing and R\&D ability & $\left(a_{22}\right)$ \\
\hline & $\left(\mathrm{U}_{2}\right)$ & Entrepreneurial strategic competencies & $\left(a_{23}\right)$ \\
\hline & & Internal Control level & $\left(a_{24}\right)$ \\
\hline & & Support level of policy & $\left(a_{31}\right)$ \\
\hline & Industry and policy risk & Industry life cycle & $\left(a_{32}\right)$ \\
\hline & $\left(\mathrm{U}_{3}\right)$ & Industry capacity & $\left(a_{33}\right)$ \\
\hline & & Industry substitutability and dependence & $\left(a_{34}\right)$ \\
\hline
\end{tabular}

